\title{
Evidenciation of Environmental Management: An Evaluation with Item Response Theory'
}

\author{
Andréa Cristina Trierweiller \\ Blênio César Severo Peixe \\ Antonio Cezar Bornia \\ Lucila Maria de Souza Campos \\ Federal University of Santa Catarina (UFSC), Florianópolis, SC, Brazil
}

Rafael Tezza

Santa Catarina State University (UDESC), Florianópolis, SC, Brazil

\begin{abstract}
The aim of this article is to measure the evidence of Environmental Management using the Item Response Theory, based on website analysis from Brazilian industrial companies. This is a qualitative, exploratory, and descriptive study related to an information collection and analysis instrument. Primary data was gathered from 638 company websites from 10 different Brazilian sectors: (1) Agricultural Production, (2) Automotive, (3) Chemicals and Petrochemical, (4) Construction, (5) Energy, (6) Paper, (7) Steel and Metals, (8) Information Technology, (9) Mining and (10) Textile. There was the creation of 26 items approved by environmental specialists. The results were attained with the measuring of Environmental Management evidence via the Item Response Theory, providing a clear order of the items involved based on each item's level of difficulty, quality, and propriety. This permitted the measurement of each item's quality and propriety, as well as that of the respondents, placing them on the same analysis scale. Increasing the number of items involved is suggested for future research in order to permit broader sector analysis. It would also be interesting to build a Computerized Adaptive Test (CAT) for the respondent - the end of the questionnaire - get, immediately, the degree of environment management evidence of your company. As such, a greater reach of the instrument should be considered with the objective to contribute to business management.
\end{abstract}

Keywords: Evidenciation, Environmental management, Websites, Measurement, Item response theory.

\section{Introduction}

In recent decades preserving and restoring the environment has become a worldwide concern. In Brazil, this concern is explicitly expressed in the 1988 Federal Constitution (Brasil, 1988) in Article 225. It states that

[...] everyone has the right to an ecologically balanced environment of common use, essential to a healthy quality of life, necessitating the government and society the duty to defend and preserve it for present and future generations. 
Furthermore, Article 23 of the same constitution states "[...] common responsibility of Federal, State, Federal District and Municipalities: [...] VI - protecting the environment and fighting pollution in any of its forms". The impacts that affect local, regional, and national economic development rely on the fact that it spreads its coverage. In fact, the social and political issues go beyond the boundaries of environmental policies which are on the agenda of various communications media as a major topic today (Brasil, 1988).

Concern for the environment has highlighted the importance of deploying an environmental management system, which can provide holistic and systemic management. According to Kaplan and Norton's (2004) assertion that it is impossible to manage something which you cannot measure reinforces the importance of using a method which provides a perspective of the business through analyzing the results of the principle strategic management perspectives. This will help executives to assess and achieve decision-making goals or to correct their courses to ensure that such objectives are achieved. In this context, there is a necessity for organizations to effectively manage their information resources and to obtain knowledge to assist the decision-making process.

As suggested by Hronec (1994), performance measurements are vital signs for an organization, confirming that environmental management requires the use of performance measurements to qualify and quantify how the activities of a process achieve their goals. Measuring the quality of this performance is important for companies as they identify aspects of the process to be improved. Constructing such a measurement is a complex task due to the latent nature of the measurement. In fact, few studies concerned with developing adequate environmental performance measurements can be found in the academic literature of business and environmental management.

Within this context, the objective of this article is to verify the viability of using the Item Response Theory to measure Environmental Management evidence among industries in Brazil, considering the sectors analyzed and based exclusively on information available in these companies' websites. The intention of such measurement is thus to evaluate the quality and propriety of each item individually, placing items and respondents on a single scale.

The Item Response Theory is a tool widely used in educational and psychological (De Ayala, 2009) and has been applied in several areas: medicine (Roos and Meares, 1998; Vidotto et al., 2006; Das and Hammer, 2005); marketing (Bayley, 2001; Singh, 2004); services (Costa, 2001); total quality management (Alexandre et al., 2002); Information Systems (Tezza et al., 2011); genetics (Tavares et al., 2004). In general, the IRT is a set of mathematical models that seeks to measure latent traits through a set of items and the construction of a scale, on the scale of the latent trait of the respondent and the difficulty of an item can be compared (Mellenbergh, 1994, Hambleton, 2000, Embretson and Reise, 2000). In this sense, the use of IRT allows: (a) to analyze items and scales, (b) create and administer measures, and (c) measuring individuals or organizations in a construct (latent trait) of interest. The TRI is supported primarily by three reasons: (a) response function of an item, (b) information function and (c) invariance (Reise et al., 2005). 
The innovation of this study is to create of a single scale on which managers are able to interpret the scale values and, consequently, to understand the meaning of achieving a certain level of environmental management performance. They can visualize the principal features of the current level of environmental management performance and can define the actions needed to improve this current level.

This article presents the following structure: Methodological Procedures, Item Response Theory, Environmental Management, Results and Discussion, Conclusions, Suggestions and References.

\section{Methodological Procedures}

The bibliographic research (secondary data) and documental analysis compose the study's theoretical reference. The primary data collection occurred exclusively on the company sites from the database of the Biggest and Best provided by Exame Magazine concerning the 10 sectors in study (Exame, 2010). Then, the researchers accessed respective websites of the companies selected and responded either "yes" or "no" to the items in the questionnaire. Thus, for the intents of this article, the industrial company environmental performance evaluation presents this delimitation and constitutes a basis to outline the current situation as well as bring together critical analysis, suggestions, and conclusions.

The inductive investigative method is utilized. As such, it starts from a particular premise, data, and confirmed facts and builds towards a general premise, a conclusion which contains unverified facts or situations.

The present study possesses a quantitative nature, related to the data collection instrument, which presents closed questions (yes or no), generating results which are thus analyzed quantitatively with a two-parameter logistic model under the Item Response Theory perspective. Such an approach results in an upgrading of ideas. This investigation involves a multi-case study in 10 economic sectors: (1) Agricultural Production, (2) Automotive, (3) Chemicals and Petrochemical, (4) Construction, (5) Energy, (6) Paper, (7) Steel and Metals, (8) Information Technology, (9) Mining and (10) Textile.

The techniques outlined and procedures utilized in collecting data were defined in 3 phases: (1) Elaborating the items based on exploratory research in literature relevant to the environment, totalling 32 items; (2) Submitting the items to evaluation from 3 experts of the environmental area, with suggestions to improve the semantics and subsequent exclusion of 6 items; and (3) Decision making regarding the final definition of the items, according Figure 1. Beside, Table 1 present the 26 final items:

The industrial companies analysed herein are ordered according to the "Sales" criteria. The data was taken from the Brazilian magazine, Exame (2010), in its annual ranking of the Biggest and Best companies performing in Brazil. Among them are national and international companies, bringing the total sample size to 638 companies under analysis. This research was carried out from August to December of 2011: (1) Agricultural Production, (2) Automotive, (3) Chemicals and Petrochemical, (4) Construction, (5) Energy, (6) Paper, (7) Steel and Metals, (8) Information Technology, (9) Mining and (10) Textile. 


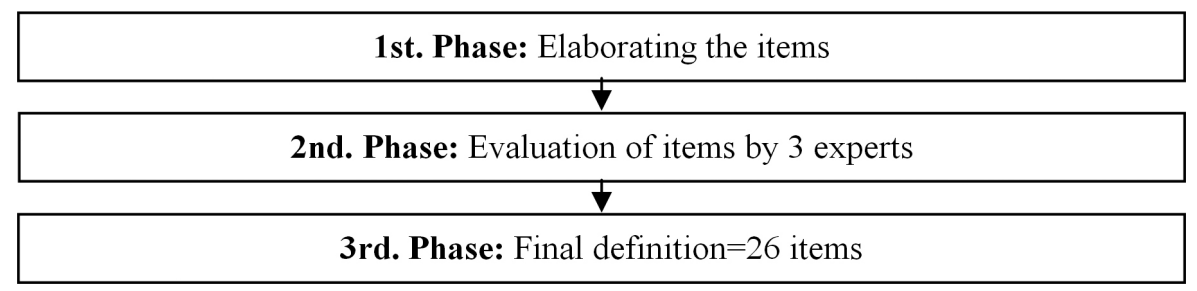

Figure 1. Phases of the study's methodological delimitation.

Table 1. Final report of the items.

\begin{tabular}{|c|c|}
\hline Numbers & Items \\
\hline 1 & Concern for environmental questions is expressed in the company's mission statement \\
\hline 2 & Concern for environmental questions is expressed in the company's vision statement \\
\hline 3 & Concern for environmental questions is mentioned in policies/directives \\
\hline 4 & The company states environmental questions in its values \\
\hline 5 & Establishes environmental goals and objectives \\
\hline 6 & Releases environmental information in a specific report \\
\hline 7 & Possesses an implemented Environmental Management System (EMS) \\
\hline 8 & Has ISO 14001 been implemented throughout the company \\
\hline 9 & Has ISO 14001 been implemented in part of its operations \\
\hline 10 & Has a structured sector/department for the environment \\
\hline 11 & Forms environmental partnerships \\
\hline 12 & Releases environmental awards \\
\hline 13 & Possesses an environmental seal \\
\hline 14 & Waste Management \\
\hline 15 & Recycling Programs \\
\hline 16 & Develops ecological products \\
\hline 17 & Efficient use/reuse of water \\
\hline 18 & Efficient use/reuse of energy \\
\hline 19 & Uses renewable energy \\
\hline 20 & Programs to mitigate/recover degraded/impacted areas \\
\hline 21 & Promotes education/training to disseminate environmental consciousness \\
\hline 22 & Possesses a greenhouse gas emission reduction process \\
\hline 23 & Fines incurred by the company are mentioned \\
\hline 24 & Possesses a foundation/institution to develop environmental projects \\
\hline 25 & The visual identity of the company (website design) is geared toward the environment \\
\hline 26 & Releases environmental information in the Global Reporting Initiative GRI pattern \\
\hline
\end{tabular}


The IRT analysis was performed with Bilog- $\mathrm{MG}^{\circledR}$ software. This software, developed by Scientific Software, Inc. (Mislevy and Bock, 1990) is one of the most popular IRT programs. The IRT model used was the two-parameter logistic model (2PLM) (Equation 1). The Bilog-MG ${ }^{\circledR}$ program performs the analysis in three phases distinguished by the type of tasks performed in each phase (Tezza et al., 2011).

\section{Item Response Theory}

The mathematical models of the IRT estimate item and respondent parameters in order to establish a quantitative measurement scale. To estimate these parameters, one defines a set of variables which cannot be measured directly, but express a theoretical concept defined by "construct" or "latent traits", such as the "environmental management performance" to be answered for a sample of manufacturers located in Brazil. The Item Response Theory (IRT) is a powerful tool that enables the construction of scales from a set of items via mathematical models (Embretson and Reise, 2000, Hambleton et al., 1991).

The IRT provides mathematical models for the latent traits, proposing forms of representing the relationship between the probability of a respondent to give a certain response to an item, and it is latent trait and items characteristics (parameters) in the knowledge field studied. A major advantage of IRT is the principle of invariance, i.e., the item parameters do not depend on the respondent's latent traits, and the individual's parameters do not depend on the items presented. Other advantages include the possibility of comparing the latent traits of individuals of different populations when they are submitted to tests or questionnaires that have certain common items. It also allows for the comparison of individuals the same population submitted to totally different tests. Lastly, this is possible because the IRT has the items as its central elements (Bortolotti et al., 2012).

For Reckase (1997), an advantage of IRT, for other tools intended for measuring the latent trait, i.e., the Classic Test Theory (CTT) that the first seal characteristics of the item and their combinations in a test as a whole. CTT assumes that the test has already been built and be alert to the score, i.e., the individual: IRT focus item, TCT focus score. Hays et al. (2000), this advantage allows the creation of a scale in which respondents and items are allocated on the same continuum. One of the limitations of CTT is that the proficiency of the respondents and the difficulty of the items cannot be estimated separately. Furthermore, in the CTT is generated only an estimated reliability and standard error of the measurements corresponding, In IRT, each item is handled individually and has a specific error for each item.

In general, the IRT models are presented using a logistic function. The more general model for analysis of unidimensional items with dichotomous response is the 3-parameter logistic model:

$$
P\left(U_{i j}=1 / \theta_{j}\right)=c_{i}+\left(1-c_{i}\right) \frac{1}{1+e^{-a_{i}\left(\theta_{j}-b_{i}\right)}}
$$


Source: Author's 3-parameter logistic model (Birnbaum, 1968).

[1] Where:

$P\left(U_{\mathrm{ij}}=1 / \theta_{\mathrm{j}}\right)$ represents the probability of a positive response;

$\theta_{\mathbf{j}}$ represents the level of the latent trait. In this case, environmental management performance of industrials;

$b_{\mathbf{i}}$ represents the difficulty of item $i$ at a certain scale and represents the value of latent variable $\theta$, In which there is 0.5 ou $\left.1+c_{\mathrm{i}}\right) / 2$ probability of the individual $j$ choosing the answer represented by $U=1$;

The coefficient $a_{\mathrm{i}}$ is the discrimination parameter of item $i$, proportional to the slope of the Item Characteristic Curve - ICC at point $b_{\mathbf{i}}$;

The parameter $c_{\mathrm{i}}$ represents the probability of a hit casual.

During the analysis process, it created a scale related to the latent trait, with mean zero and standard deviation one, the parameters of the items are estimated (a, b, c). In the estimates are generated Characteristic Curves of the Items (CCI), in these curves there is the probability of hitting the item depending on the skill of the respondent $(\theta)$.

With IRT the respondents and items are located on the same scale (metric). The responses given by a group of respondents to a measuring instrument is used for the estimation of the items and the respondents in this same scale. For an item to be useful, it must be able to differentiate between respondents located in different points along the scale. Respondents are characterized by their position on the latent variable and items are characterized according to their position and capacity to discriminate between respondents (De Ayala, 2009).

According Bortolotti et al. (2012) several IRT models were developed and the main distinction between these models refers to the assumption about the relation between the answer choices of a question and the level of the latent trait. There are two types of response processes, the cumulative one and the unfolding one. Cumulative and unfolding models were developed for dichotomous or binary data and polytomous, nominal or graded, parametric and non-parametric models and unidimensional and multidimensional models. Cumulative IRT models are built on the notion in which the probability of an individual giving or choosing an affirmative answer to an item increases as his latent trait increases, i.e., higher levels of latent trait lead to a higher probability of affirmative answers, resulting in a monotonic behavior in the CCI. In this study is was used the cumulative IRT model for items with dichotomous responses (right/wrong). Three models are presented: the 1-parameter logistic model referred as the Rasch Model (1PL), the 2-parameter logistic model (2PL) and the 3-parameter logistic model (3PL). The 2-parameter logistic model is defined as:

$$
P\left(\theta_{j}, a_{i}, b_{i}\right)=\frac{1}{1+e^{-a_{i}\left(\theta_{j}-b_{i}\right)}}
$$

In this model, $b_{\mathbf{i}}$ is the difficulty parameter of item $i$, represented on the same scale as the latent trait $\theta_{\mathrm{j}}$, and $a_{\mathrm{i}}$ is the discrimination (or inclination) parameter of item $i$. Usually, $b$ is represented on a scale with mean zero and standard deviation one. The 
Item Characteristic Curve (ICC) represents the $P\left(\theta_{\mathrm{i}}, a_{\mathrm{i}}, b_{\mathrm{i}}\right)$ relationship with respect to the probability of a certain response to an item, the respondent's latent traits and the item's parameters (Santor et al., 1994).

The majority of IRT models, including the two parameter logistics model, are based on the assumption that the items measure a single latent and continuous value $\theta$, varying from $-\infty$ to $+\infty$, or rather, that presumes uni-dimensionality of the construct.

Uni-dimensionality of a scale may be evaluated through factorial analysis. Factorial analysis most frequently found in relevant literature is exploratory and confirmatory. However, for dichotomous responses, these approaches present some mathematical limitations resolved using the approach described by Bock and Aitkin (1981) and Bock et al. (1988), in which dichotomous item treatment and factor weight loads are performed through the technique called full information factor analysis, based on the item response theory. According to Reeve (2002) the uni-dimensionality assumption may be examined comparing the relationship between the first and second eigenvalue from the tetrachoric correlations matrix. This is an indicator of first dimension strength of the data. According to Reckase (1979), if the first factor explains $20 \%$ or more of the variance of the set, one can thus assume uni-dimensionality. The dimensionality of a set of data may also be verified by means of testing the variance analysis (Anova), Chi-squared, Akaike's information criteria, and others (Chalmers, 2011).

In this article, the results show unidimensionality, with the first factor explaining $69 . \%$ of the total variance, as seen in Figure 2:

Another basic assumption of the IRT is local interdependence, which signifies that if the level of the trait is maintained Constant, there should not be any association

\section{Scree plot}

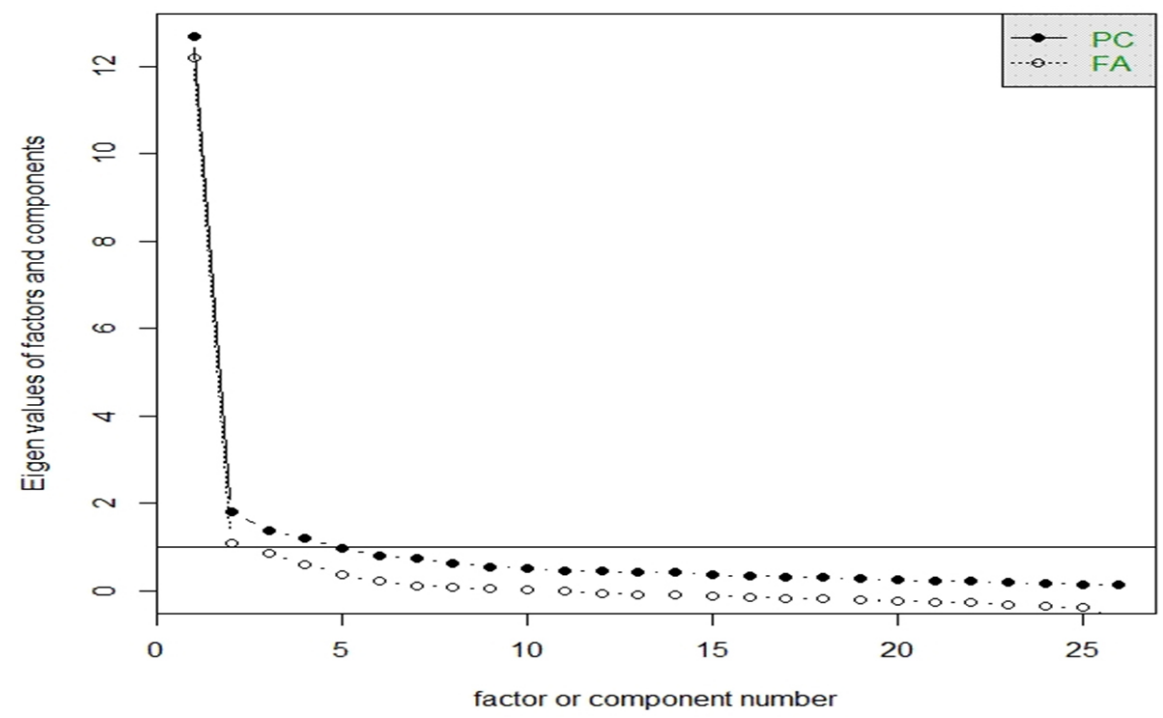

Figure 2. Factorial Analysis. 
between the item responses (Thissen and Steinberg, 1988). The lack of either of these two assumptions may generate unstable and inconsistent estimates.

The construction of a set of items as well as a scale to measure the environmental management performance of industrials based on IRT is proposed. This study is structured as follows: (1) the context of the study is presented, followed by an explanation of scale construction, the IRT, and industrial company environmental management performance; (2) the methodology is described; (3) the findings are presented and then discussed, and finally; (4) the conclusions.

It is possible to establish a scale to measure the Brazilian industrial environmental management performance and to follow its evolution over time. It is also possible that new firms, responding to all items, check what their level is on the scale. The scale can be constantly updated with the inclusion of new items, ensuring comparison by keeping the same established unit of measurement. This results in a calibrated item database in the performance range of environmental management, which can be extended to evaluate other industries throughout Brazil.

\section{Environmental Management}

Companies increase their trend to market value if they state that they are adopting environmental management systems (Jacobs et al., 2010). Thus, the environmental information Expressed through official company website is a good way for Evaluate environmental performance in the whole industry.

Previous studies of environmental management in Brazil include, Jabbour et al. (2012), Trierweiller et al. (2012, 2011), Jabbour (2010), Jabbour and Santos (2009), Gavronski et al. (2008), Seiffert (2008), Shigunov Neto et al. (2009), Nascimento et al. (2008) and Barbieri (2007).

Jabbour et al. (2012) analyzed if environmental management can be considered a new competitive priority for manufacturing enterprises located in Brazil. A cross-sectional survey was conducted with Brazilian companies certified by ISO 14001. Sixty-five valid questionnaires were analyzed through Structural Equation Modeling (SEM). The first conclusion is that environmental management presents a preventive approach in the sample analyzed, focused on eco-efficiency, what potentially do not to create a competitive advantage. This preventive approach inhibits environmental management from being regarded as a new competitive manufacturing priority, in the full sense as defined by the literature. Another important result is that environmental management, although following a preventive focus, may influence positively the four manufacturing priorities: cost, quality, flexibility and delivery.

Trierweiller et al. (2011) point out that the standards of ISO 14001 does not require the organization's optimal level of environmental performance, however, describe a system to help them achieve their own goals.

Gavronski et al. (2008) did a survey with 63 Brazilian companies from the chemical, mechanical and electronic industries. A Structural Equations Model (SEM) analyzed the relations between motivations and benefits related to the certification. An exploratory factor analysis identified four sources of motivation: reaction to pressures from the external stakeholders; proaction in expectation of future business concerns; 
legal concerns; and internal influences. Four dimensions characterized the benefits of an ISO 14001 certification: operational changes; financial impacts; relationship with business stakeholders (customers, competitors, suppliers); and relationship with societal stakeholders (government, society and NGOs). The motivations appear in two levels. Internal and legal motivations are the first level (antecedents), while reactive and proactive motivations are second level (consequents). Internal motivations explain reactive and proactive motivations and production benefits. Legal motivations explain proactive motivations, financial benefits, and benefits in relationships with societal stakeholders.

According Seiffert (2008) the certification of an ISO 14001 Environmental Management System (EMS) is currently an important requirement for those enterprises wishing to sell their products in the context of a global market. The system's structure is based on Environmental Impact Evaluation (EIE). However, if an erroneous or inadequate methodology is applied, the entire process may be jeopardized. Many methodologies have been developed for making of EIEs, some of them are fairly complex and unsuitable for EMS implementation in an organizational context, principally when small and medium size enterprises (SMEs) are involved. The proposed methodology for EIE is part of a model for implementing EMS. The methodological approach used was a qualitative exploratory research method based upon sources of evidence such as document analyses, semi-structured interviews and participant observations. By adopting a cooperative implementation model based on the theory of system engineering, difficulties relating to implementation of the sub-system were overcome thus encouraging SMEs to implement EMS.

The definitions of corporate environmental management share the inclusion of a systematic approach to the appropriate consideration of environmental issues at all organizational levels from strategic to operational and from theoretical to applied (Jabbour, 2010). In this sense, the logic of the cycle PDCA directed the production of ISO 14001 in the implantation of the Environmental Management System, which is based on the continuous improvement (Brandli et al., 2011).

Regarding the strategic environmental management, Doriguel (2012) in a study with aims to analyze a company hydraulic assembly, addressing the potential contributions of Lean Manufacturing for environmental management (Green Management) concluded that the knowledge level of employees and managers on the subject under study, so there is ignorance on both sides. Veiga et al. (2011) conducted a research comparing study experts' view of the strategic role of lean. The results support that lean can generate a strong advantage in diverse competitive dimensions; but, a formal strategy approach needs to concentrate in the model implementation.

Jabbour and Santos (2009) highlight the fundamental role of human resources and implementation of environmental management systems. They state that while the specialized literature concerning the technical aspects of environmental management expands, there is a gap in the bibliography: integrated approaches between human resource dimensions and environmental management. A model that analyses the relationships between these dimensions and the typical phases of an environmental management system is presented, within a perspective of application for academicians and managers. 
According Shigunov Neto et al. (2009): Environmental management may be defined as the set of management function activities which determine the environmental policy, objectives, and responsibilities of the company and place them into practice through intermediaries of the environmental system, environmental planning, environmental control, and environmental management improvement. As such, environmental management is the efficient management of the organization's relationship with the environment.

Companies seek to demonstrate and secure effective and efficient environmental performance control in order to reach sustainable development within the objectives and goals defined by high management. In order to do so, it is necessary to integrate the components of company environmental management, evidencing the diverse areas involved in the organization's structure. This view points to implementing policies and directives which orient the decision making process in all the actions developed in order to demonstrate the permanent strategy of investing through environmental management systems in the generation of expected results, defined in the objectives outlined by organizations.

Companies demonstrate the maturity of environmental management through environmental disclosure; that is, evidencing the environmental information to stakeholders. Sobhani et al. (2012) based on the annual reports and corporate websites of the banking industry in Bangladesh described the disclosure practices of corporate sustainability. It is verified in the study that, to varying degrees, all listed banks practice sustainability disclosure in an unstructured way in both the annual reports and corporate websites. It was found that the social dimension is generally evidenced unlike the environmental and economic dimensions.

Nascimento et al. (2008) defines the Environmental Management System (EMS) as: the set of procedures which will help the organization to understand, control, and reduce the environmental impacts of its activities, products, and/or services. They also add that an efficient EMS permits companies to improve the management of environmental aspects and impacts, beyond interacting in changing organizational attitudes and cultures, improving its results in economic terms upon acting towards the continued improvement of processes and services. Barbieri (2007) also highlights the importance of placing environmental issues strategically in the organization.

In interesting study conducted by Park and Ahn (2012) with Korean construction industry, they verified that various Korean industries have integrated environmental issues into their corporate strategies in response to Sustainable Development paradigms, climate change issues and others reasons. However, according to the analyses of this study, a total of 24 out of the top 100 Korean constructors corresponded to stage 1 . That is, unaware of the necessity of environmental management, and were ranked to be the lowest, according Hunt and Auster's (1990) model as the "Beginner."

Based on the results of the EMS, the company must carry out critical analysis in order to attend its stakeholders' demands and legal aspects in seeking constant perfection. It is thus fundamental to contemplate the environmental management areas with critical analysis, based on a total environmental evaluation, as shown in Figure 3: 


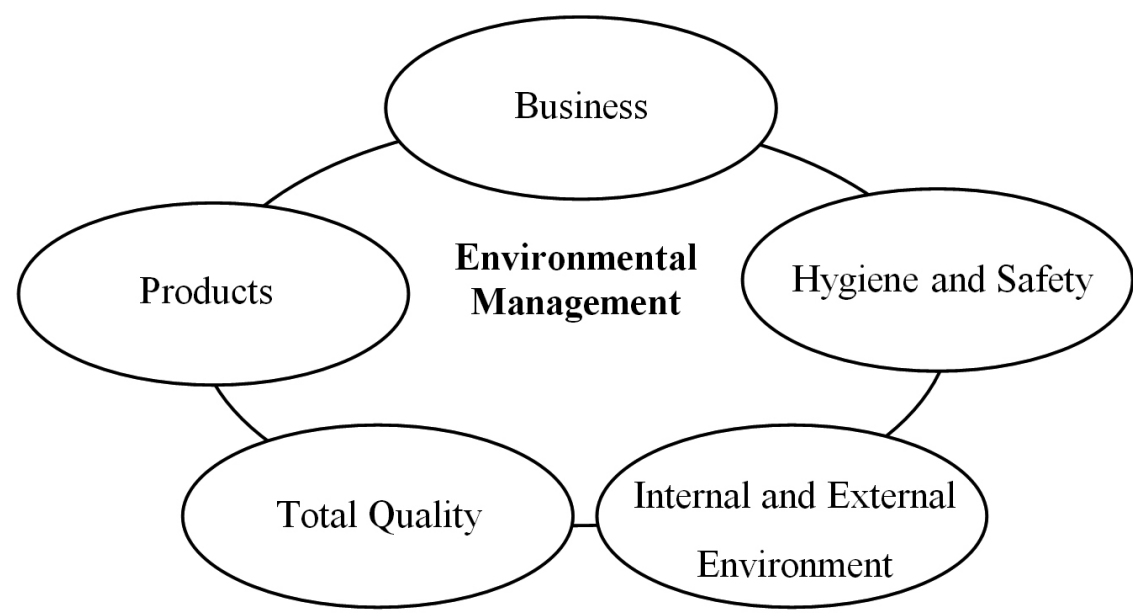

Figure 3. Components of Environmental Management.

The integration of these concepts provides the company with a differential which is recognized and valued by the market. However, it cannot be represented or directly measured through a single element, but rather through a set of attributes which can evidence competitive advantage.

The consequences of environmental management performance should not be restricted to the interests of the company in terms of operational efficiency and costs but should reach strategic levels and all stakeholders. For this reason, measuring environmental management performance is fundamental for opening these borders. Zeng et al. (2008) state that environmental management and ISO 14001 are relevant to the growth of international sales.

\section{Results and Discussion}

Table 2 demonstrates the estimated parameters for the 26 items based on the sample of 638 companies from the sectors under analysis. These items were ordered according to their Level of difficulty, represented by the parameter " $b$ ". The parameters were estimated according to a normal distribution $\mathrm{N}(0,1)$, in other words with a mean of zero and a variance of one.

In practical terms, based on the parameter $b$, it is more probable that companies which have a degree of Environmental Management evidence surrounding the mean (in this case, zero) possess the majority of the characteristics evidenced in the items. Merely 4 items demonstrate a greater level of difficulty, with one above 1. These items are: item $23(b=1.555)$, item $8(b=1.457)$, item $2(b=1.369)$ and 13 (1.333). Thus, the company must be able to attend the set of items elaborated in order to evidence its Environmental Management. In other words, the instrument as a whole showed low levels of difficulty.

Item 23 "Fines incurred by the company are mentioned" $(b=1.555)$ is the most difficult of the 26 , meaning that the majority of the organizations did not 
Table 2. Parameters of the ordered items according to degree of difficulty (expressed by the parameter b).

\begin{tabular}{|c|c|c|c|c|}
\hline Items & $\mathrm{a}$ & $\mathrm{SE}$ & $\mathrm{b}$ & SE \\
\hline $\mathrm{I} 23$ & 2.433 & 0.342 & 1.555 & 0.082 \\
\hline I08 & 0.808 & 0.127 & 1.457 & 0.195 \\
\hline I02 & 1.286 & 0.151 & 1.369 & 0.124 \\
\hline $\mathrm{I} 13$ & 1.908 & 0.229 & 1.333 & 0.093 \\
\hline I 26 & 3.777 & 0.417 & 0.979 & 0.047 \\
\hline I01 & 1.281 & 0.134 & 0.901 & 0.096 \\
\hline I24 & 3.579 & 0.354 & 0.891 & 0.047 \\
\hline I12 & 2.177 & 0.211 & 0.749 & 0.059 \\
\hline I06 & 3.624 & 0.355 & 0.720 & 0.043 \\
\hline I04 & 1.409 & 0.136 & 0.584 & 0.073 \\
\hline I11 & 3.715 & 0.387 & 0.542 & 0.043 \\
\hline I09 & 1.452 & 0.152 & 0.535 & 0.070 \\
\hline $\mathrm{I} 10$ & 2.981 & 0.264 & 0.534 & 0.044 \\
\hline I19 & 2.852 & 0.275 & 0.487 & 0.045 \\
\hline I 22 & 2.639 & 0.250 & 0.470 & 0.045 \\
\hline I16 & 2.369 & 0.212 & 0.407 & 0.048 \\
\hline I05 & 3.297 & 0.342 & 0.392 & 0.041 \\
\hline I18 & 4.421 & 0.507 & 0.348 & 0.032 \\
\hline I 20 & 3.524 & 0.367 & 0.300 & 0.037 \\
\hline I17 & 4.263 & 0.426 & 0.229 & 0.034 \\
\hline $\mathrm{I} 07$ & 2.485 & 0.242 & 0.191 & 0.045 \\
\hline I 21 & 3.191 & 0.325 & 0.153 & 0.039 \\
\hline I15 & 3.823 & 0.331 & 0.094 & 0.038 \\
\hline I03 & 2.568 & 0.240 & 0.083 & 0.045 \\
\hline $\mathrm{I} 25$ & 2.914 & 0.226 & 0.069 & 0.043 \\
\hline I14 & 4.636 & 0.447 & -0.030 & 0.035 \\
\hline
\end{tabular}

provide evidence they declared that they were fined due to punitive action concerning environmental questions, as determined by supervisory fiscal organizations.

Item 8 is the second most difficult of the 26 items: "Has ISO 14001 been implemented throughout the company" $(\mathrm{b}=1.457)$, meaning that the majority of the organizations did not provide evidence of having the ISO 14001 implemented throughout the company. However, this item showed the least discriminatory power, as represented by the parameter $(a=0.808)$. This parameter represents the item's quality with respect to its information. However, even with the lesser parameter "a" compared to those remaining it is still above 0.7 , as recommended by literature: items with low "a" values (generally less than 0.7 ): “[...] a low discrimination parameter of a $<0.700$, 
which indicated items offering little information and possibly not directly related to the latent trait." (Tezza et al., 2011, p. 171).

Item 2 "Concern for environmental questions is expressed in the company's vision statement" $(\mathrm{b}=1.369)$, the third most difficult, demonstrates that not all companies mention concerns for environmental questions in declaring their vision. However, the mission statement, represented by item $1(b=0.901)$. It demonstrated greater evidence as these two items are inherent to the company's strategic formulations.

Item 13 "Possesses an environmental seal" $(b=1.333)$, which refers to the environmental seal, is characterized as difficult for companies to evidence.

Item $14(b=-0.030)$ showed itself to be the easiest. This means that the Waste Management is the most common aspect adopted by the companies in order to demonstrate their environmental management.

In the item 25 "The visual identity of the company (website design) is geared toward the environment" $(b=0.069)$, showed itself to be the second easiest. This means that the companies analysed tend to evidence their visual identity related to the environmental question, which may facilitate that the user identifies environmental practices of these organizations.

In item $3(b=0.083)$, the third easiest item, one observes that the majority of the companies present the mention of concern for environmental questions in their strategic policies and directives. This may be related to the fact that the definition of environmental variables inserted into the organization's directives is guided by its strategy to simulated scenarios within the environmental conjecture. Thus, one verifies the company tendency to initiate their strategic planning with focus, including in sustainability questions, concerning themselves primarily with their environmental policy definition.

Items 12 "Releases environmental awards" and 6 "Releases environmental information in a specific report" with respective "b" parameters of 0.749 and 0.720 showed to be very close in their positioning on the scale, which indicates they are at the same level as attending Environmental Management. This demonstrates that the company values transparency in releasing environmental information to their stakeholders with respect to their actions concerning awards obtained and disclosed in their annual reports.

Items 19 "Uses renewable energy", 22 "Possesses a greenhouse gas emission reduction process" and 16 "Develops ecological products" with respective "b" parameters of $0.487,0.470$ and 0.407 showed to be very close in their positioning on the scale, which indicates they are at the same level as attending Environmental Management. Such positioning demonstrates that companies concerned with releasing information related to eco-efficiency programs.

Items 5 "Establishes environmental goals and objectives", 18 "Efficient use/ reuse of Energy" and 20 "Programs to mitigate/recover degraded/impacted areas" with respective " $b$ " parameters of $0.392,0.348$ and 0.300 showed to be very close in their positioning on the scale, which indicates they are aligned as attending Environmental Management. This indicates that efficient energy use as well as prevention programs and mitigation to degraded areas show themselves to be related to the environmental 


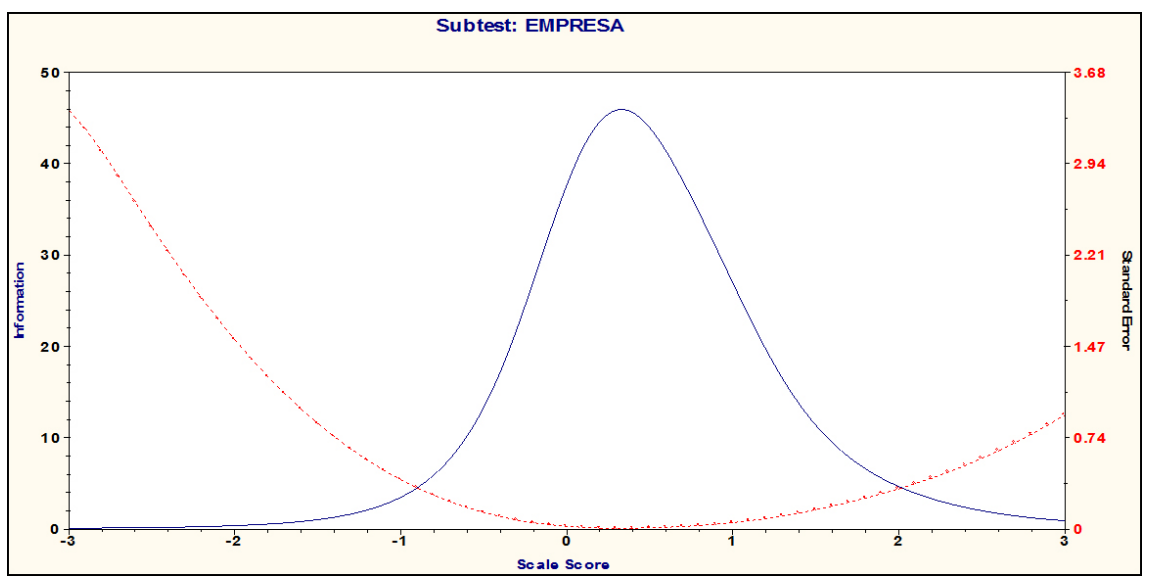

Figure 4. Total information curve for the test (function test information: continuous line; standard error of measurement: dotted line).

policies of the companies analyzed. Figure 4 refers to the total information curve, which is represented by the sum of the information from all the items.

It demonstrates that the construct presents precision above the mean in order to measure the Degree of Evidencing Company Environmental Management among the sectors analysed.

\section{Conclusions}

Based on the results obtained, one can verify the viability of measuring and thus evidencing Environmental Management among the companies in the analyzed sectors, using the IRT. In fact, it has presented many advantages with respect to item selection in composing the questionnaire, as it permits quality and propriety evaluation for each item individually while placing them within a single scale: items and respondents, which is not possible through the use of other tools. This is useful when evaluating constructs which are difficult to observe or abstract, such as evaluating Environmental Management.

One can observe a clear order of the items based on each item's estimated level of difficulty as well as each item's quality. Thus, characteristics related to fines disclosed (Item 23) and possessing ISO 14001 throughout the company (Item 8) are verified as little practiced by companies in the scale generated and possess a greater level of difficulty than the remaining items.

It was observed that the disclosure of environmental information, both in companies that exhibit sustainability report as those in which this information is placed in a dispersed on their website, the tendency to self-promotion. That is, in relation to fines (item 23), which is information with a negative connotation, and not usually evident, but when there is mention, the focus is placed on mitigation actions and legal providences taken by the company to contest these violations. 


\section{Suggestions}

As to the limitations of the company Environmental Management Evidence evaluation questionnaire, presented in Table 1, construction of a greater number of items it suggested and their continuous improvement.

It would also be interesting to build software for the respondent - the end of the questionnaire - get, immediately, the degree of environment management evidence of your company. As such, a greater reach of the instrument should be considered with the objective to contribute to business management.

\section{Acknowledgements}

We would like to thank the Coordination for the Improvement of Personnel of Superior Level (Coordenação de Aperfeiçoamento de Pessoal de Nível Superior - CAPES), Brazil, that supported this study.

\section{References}

Alexandre, J.W.C.; Andrade, D.F.; Vasconcelos, A.P. and Araujo, A.M.S. (2002) Uma proposta de análise de um construto para a medição dos fatores críticos da gestão pela qualidade através da teoria da resposta ao item. Gestão \& Produção, Vol. 9, No. 2, pp. 129-141. http://dx.doi.org/10.1590/S0104-530X2002000200003

Barbieri, J.C. (2007) Gestão ambiental empresarial (Corporate environmental management). São Paulo: Saraiva. Vol. 1, No. 1.

Bayley, S. (2001) Measuring customer satisfaction. Evaluation Journal of Australasia,

Birnbaum, A. (1968) Some latent trait models and their use in inferring an examinee's ability, contributed chapters, in: Lord, F.M. and Novick, M.R. (Eds.), Statistical Theories of Mental Test Scores. Reading: Addison Wesley.

Bock, R.D. and Aitkin, M. (1981) Maginal maximum likelihood estimation of item parameters: Application of an EM algorithm. Psychometrika, Vol. 46, pp. 443-445. http://dx.doi. org/10.1007/BF02293801

Bock, R.D.; Gibbons, R. and Muraki, E. (1988) Full information item factor analysis. Applied Psychological Measurement, Vol. 12, pp. 261-280. http://dx.doi. org/10.1177/014662168801200305

Bortolotti, S.L.V.; Tezza, R.; Andrade, D.F.; Bornia, A.C. and Sousa Júnior, A.F. (2012) Relevance and advantages of using the item response theory. Quality and Quantity, Vol. 46, pp. 714-728.

Brandli, L.L.; Frandoloso, M.A.L. and Tauchen, J. (2011) Improving the environmental work at University of Passo Fundo, Brazil - towards an Environmental Management System. Brazilian Journal of Operations \& Production Management, Vol. 8, No. 1, pp. 31-54. http:// dx.doi.org/10.4322/bjopm.2011.002

Brasil. Constituição (1988) Constituição da República Federativa do Brasil. (Federal Constitution, 1988). Brasília: Senado Federal.

Chalmers, P. (2011) Package 'mirt' verson 1-16. Obtido em 11 de 01 de 2011. The R Project for Statistical Computing. Available: www.r-project.org.

Costa, M.B.F. (2001) Técnica derivada da Teoria de Resposta ao Item (TRI) aplicada ao setor de serviços. Dissertação. Programa de Pós-Graduação em Métodos Numéricos em Engenharia. Federal University of Paraná, Curitiba. 
Das, J. and Hammer, J. (2005) Which doctor? Combining vignettes and item response to measure clinical competence. Journal of Development Economics, Vol. 78, pp. 348-383. http:// dx.doi.org/10.1016/j.jdeveco.2004.11.004

De Ayala, R.J. (2009) The theory and practice of Item Response Theory. New York: The Guilford Press -New York Wiley.

Doriguel, F. (2012) Lean and green: an analysis in of potential contributions lean manufacturing for the environmental management in a company of sector hydraulic assembly. Tékhne $\varepsilon$ Lógos, Vol. 3, No. 2.

Embretson, S.E. and Reise, S.P. (2000) Item response theory for psychologists. New Jersey: Lawrence Erlbaum Associates.

Exame. (2010) Maiores e Melhores, Maiores empresas por vendas em 2010. Revista Exame, 07 ago. Available: http://exame.abril.com.br/negocios/melhores-e-maiores.

Gavronski, I.; Ferrer, G. and Paiva, E.L. (2008) ISO 14001 certification in Brazil: motivations and benefits. Journal of Cleaner Production, Vol. 1, pp. 87-94. http://dx.doi. org/10.1016/j.jclepro.2006.11.002

Hambleton, K.; Swaminathan, H. and Rogers, H.J. (1991) Fundamentals of item response theory. Newbury Park: Sage.

Hambleton, R.K. (2000) Emergence of Item Response Modeling in instrument development and data analysis. Medical Care, Vol. 38, No. 9 (Supplement II), pp. 60-65.

Hays, R.D.; Morales, L.S. and Reise, S.P. (2000) Item Response Theory and Health Outcomes Measurement in the 21st Century. Medical Care, Vol. 38, No. 9, pp. II-28-II-42.

Hronec, S.M. (1994) Sinais vitais (Vital signs). São Paulo: Makron Books.

Jabbour, C.J.C. (2010) Greening of business schools: a systemic view. International Journal of Sustainability in Higher Education, Vol. 11, No. 1, pp. 49-60. http://dx.doi. org/10.1108/14676371011010048

Hunt, C.B. and Auster, E.R. (1990) Proactive environmental management: avoiding the toxic trap. Sloan Management Review, Vol. 31, No. 2, pp. 7-18.

Jabbour, C.J.C. and Santos, F.C.A. (2009) Relationships between human resource dimensions and environmental management in companies: proposal of a model. Journal of Cleaner Production, Vol. 16, pp. 51-58. http://dx.doi.org/10.1016/j.jclepro.2006.07.025

Jabbour, C.J.C.; Silva, E.M.; Paiva, E.L. and Santos, F.C.A. (2012) Environmental management in Brazil: is it a completely competitive priority? Journal of Cleaner Production, Vol. 21, pp. 11-22. http://dx.doi.org/10.1016/j.jclepro.2011.09.003

Jacobs, B.W.; Singhal, V.R. and Subramanian, R. (2010). An empirical investigation of environmental performance and the market value of the firm. Journal of Operations Management, Vol. 28, No. 5, pp. 430-441. http://dx.doi.org/10.1016/j.jom.2010.01.001

Kaplan, R.S. and Norton, D.P. (2004) Mapas estratégicos: balanced scorecard: convertendo ativos intangíveis em resultados tangíveis. Rio de Janeiro: Elsevier.

Mellenbergh, G.J. (1994) Generalized linear item response theory. Psychol Bull Journal, Vol. 15, pp. 300-307. http://dx.doi.org/10.1037/0033-2909.115.2.300

Mislevy, D.J. and Bock, R.D. (1990) BILOG: Item Analysis and Test Scoring with Binary Logistic Models [Computer Program] Chicago: Scientific Software.

Nascimento, F.L.; Lemos A.D.C. and Mello, M. C. A. (2008) Gestão socioambiental estratégica. Porto Alegre: Bookman.

Park, J. and Ahn, Y. (2012) Strategic environmental management of Korean construction industry in the context of typology models. Journal of Cleaner Production, Vol. 23, pp. 158-166. http://dx.doi.org/10.1016/j.jclepro.2011.10.032 
Reckase, M.D. (1979) Unifactor latent trait models applied to multifactor tests: Results and implications. Journal of Educational Statistics, Vol. 4, pp. 207-230. http://dx.doi. org/10.2307/1164671

Reckase, M.D. (1997) A linear logistic multidimensional model for dichotomous item response data, in: Van der Linden, W.J. and Hambleton R.K. (Eds.), Handbook of modern item response theory. New York: Springer- Verlag, pp. 271-286. http://dx.doi.org/10.1007/9781-4757-2691-6_16

Reeve, B.B. (2002) An introduction to modern measurement theory. Bethesda: National Cancer Institute.

Reise, S.P.; Ainsworth, A.T. and Haviland, M.G. (2005) Item Response Theory: Fundamentals, Applications, and Promise in Psychological Research. Current Directions in Psychological Science, Vol. 14, No. 2, pp. 95-101. http://dx.doi.org/10.1111/j.09637214.2005.00342.x

Roos, Y. and Meares, P.A. (1998). Aplication of Rasch analysis: Exploring differences in depression between African-American and White children. Journal of Social Service Research, Vol. 23, No. 3-4, pp. 93-107. http://dx.doi.org/10.1300/J079v23n03_06

Santor, D.A.; Ramsay, J.O. and Zuroff , D.C. (1994) Nonparametric item analyses of the Beck Depression Inventory. Examining item bias and response option weights in clinical and nonclinical samples. Psychological Assessment, Vol. 6, pp. 255-270. http://dx.doi. org/10.1037/1040-3590.6.3.255

Seiffert, M.E.B. (2008) Environmental impact evaluation using a cooperative model for implementing EMS (ISO 14001) in small and medium-sized enterprises. Journal of Cleaner Production, Vol. 16, pp. 1447-1461. http://dx.doi.org/10.1016/j.jclepro.2007.10.001

Shigunov Neto, A.; Campos, L.M.S. and Shigunov, T. (2009) Fundamentos da Gestão Ambiental. Rio de Janeiro: Ciência Moderna.

Singh, J. (2004) Tackling measurement problems with Item Response Theory: principles.; characteristics, and assessment, with an illustrative example. Journal of Business Research, Vol. 57, pp. 184-208. http://dx.doi.org/10.1016/S0148-2963(01)00302-2

Sobhani, F.A.; Amran, A. and Zainuddin, Y. (2012) Sustainability disclosure in annual reports and websites: a study of the banking industry in Bangladesh. Journal of Cleaner Production, Vol. 23, pp. 75-85. http://dx.doi.org/10.1016/j.jclepro.2011.09.023

Tavares, H.R.; Andrade, D.F. and Pereira, C.A. (2004) Detection of determinant genes and diagnostic via item response theory. Genetics and Molecular Biology, Vol. 27, No. 4, pp. 679-685. http://dx.doi.org/10.1590/S1415-47572004000400033

Tezza, R.; Bornia, A.C. and Andrade, D.F. (2011) Measuring web usability using item response theory: principles, features and opportunities. Interacting with Computers, Vol. 23, pp. 167-175. http://dx.doi.org/10.1016/j.intcom.2011.02.004

Thissen, D. and Steinberg, L. (1988) Data analysis using item response theory. Psychological Bulletin, Vol. 104, 385-395. http://dx.doi.org/10.1037/0033-2909.104.3.385

Trierweiller, A.C.; Peixe, B.C.S; Campos, L.M.S. and Bornia, A.C. (2011) Selection Process Theoretical Framework: Environmental Performance Evaluation, in: 3rd International Workshop Advances in Cleaner Production, São Paulo.

Trierweiller, A.C.; Peixe, B.C.S.; Tezza, R.; Bornia, A.C.; Andrade, D.F. and Campos, L.M.S. (2012) Environmental management performance for Brazilian industries: measuring with the item response theory. Work, Vol. 41, pp. 2179-2186. http://dx.doi.org/10.3233/WOR2012-1023-2179 
Veiga, G.L.; De Lima, E.P.; Angelis, J.J. and Costa, S.E.G. (2011) The Strategic Role of Lean - A Discussion. Brazilian Journal of Operations \& Production Management, Vol. 8, No. 1, 9-30. http://dx.doi.org/10.4322/bjopm.2011.001

Vidotto, G.; Bertolotti, G.; Carone, M.F.; Arpinelli, F.; Bellia, V.; Jones, P.W. and Donner, C.F. (2006) A new questionnaire specifically designed for patients affected by chronic obstructive pulmonary disease: The Italian Health Status Questionnaire. Respiratory Medicine, Vol. 100, No. 5, pp. 862-870. http://dx.doi.org/10.1016/j.rmed.2005.08.024

Zeng, S.X.; Xie, X.M.; Tam, C.M. and Wan, T.W. (2008) Competitive priorities of manufacturing firms for internationalization: an empirical research. Measuring Business Excellence, Vol. 12, No. 3, pp. 44-55. http://dx.doi.org/10.1108/13683040810900395

\section{Biography}

Andréa Cristina Trierweiller is Dr. (2010) and M.Sc. (2004) at Production Engineering by Federal University of Santa Catarina. She is Administrator (1993) by Federal University of Santa Catarina. Since October 2010, she is Post Graduate Researcher, at Department of Production Engineering at Federal University of Santa Catarina, Brazil. She has research interests in the area of environmental management and applications of Item Response Theory.

Contact: andreatri@gmail.com

Blênio César Severo Peixe is Dr. (2005) at Business Sciences by UMSA (Argentina, 2005) and currently he is doing his doctorate in Production Engineering by Federal University of Santa Catarina. He is Permanent Adjunct Professor at the Federal University of Paraná, Brazil. He has research interests in the area of managerial accounting, environmental accounting, environmental management and applications of Item Response Theory.

Contact: bleniocsp@gmail.com

Rafael Tezza is an Assistant Professor in the Department of Business Administration, Santa Catarina State University, Brazil. He received his B.Eng. and M.Eng from Federal University of Santa Catarina in 2006, 2009, respectively. Currently conducts researches at the doctorial course in the same department. His research are focuses in Item Response Theory, e-commerce and statistical modeling.

Contact: rafaeltezza@yahoo.com.br

Antonio Cezar Bornia is Dr. (2005) at Production Engineering by Federal University of Santa Catarina. He is Permanent Associate Professor at the Federal University of Santa Catarina at Department of Production Engineering, and PostGraduate Program in Production Engineering at Federal University of Santa Catarina, Brazil. He has experience in Production Engineering with emphasis on Cost Analysis and applications of Item Response Theory.

Contact: cezar@deps.ufsc.br

Lucila Maria de Souza Campos is Dr. (2001) and M.Sc. (1996) at Production Engineering by Federal University of Santa Catarina. She is Production Engineer (1993) by Federal University of São Carlos and Administrator (2009) by Itajai Valley University (UNIVALI). Since March 2010, she is Permanent Adjunct Professor, at Department of Production Engineering, and Post-Graduate Program in Production Engineering at 
Federal University of Santa Catarina, Brazil. She has research interests in the area of environmental management.

Contact: lucila@deps.ufsc.br

\section{Article Info:}

Received: August, 2012

Accepted: October, 2012 